\title{
Implications of Fracture Network Mapping in the Palaeozoic Limestone of the Kinta Valley, Malaysia
}

\author{
Maryam S. Dzulkefli ${ }^{1}$, L. Ducarme ${ }^{2}$, S. Kassa ${ }^{1}$ and B.J. Pierson ${ }^{1}$ \\ ${ }^{1}$ Universiti Teknologi PETRONAS, Tronoh, Perak, Malaysia \\ ${ }^{2}$ Beicip-Franlab, France
}

The Palaeozoic limestone exposed at Tambun, near Ipoh, Malaysia, displays spectacular fracture networks. Fractures were mapped on a vertical cliff face representing the top of a vertically-dipping bed, striking approximately N-S. Four major fracture sets cover the bed surface: vertical fractures, horizontal fractures and 2 sets of oblique fractures. The vertical fractures are orientated along an east-west plane. The density of vertical fractures is the highest, with a frequency that is locally less than $2 \mathrm{~cm}$. The horizontal fractures dip slightly to the east, locally show a displacement along the vertical fractures and have a frequency of about $10 \mathrm{~cm}$. The oblique fractures are shear fractures, are at about $40^{\circ}$ and $50^{\circ}$ to the vertical fractures, respectively and have a frequency of about $50 \mathrm{~cm}$. Mapping the fracture networks indicates a $\sigma_{1}$ orientated along an east-west axis and an $\sigma_{3}$ orientated along a north-south axis. The fractures are the result of a compressional stress, along an east-west axis and have created a significant fracture porosity at the location of the Tambun outcrop. Similar fracture systems could be found in subsurface Palaeozoic limestones, including the ones that form fractured oil reservoirs in SE Asia. The measured outcrops could therefore be used as analogues. 